\title{
BIKE TOWN ORGANIC JUICE
}

Por: Sebastian Franky

Las buenas creaciones nacen de juntes extraordinarios, dos tendencias actuales se unen para crear una nueva propuesta de valor con grandes ventajas competitivas que pronto emergerá al mercado para generar una nueva experiencia en el consumidor.

El uso de la bicicleta como medio de transporte alternativo en la ciudad de Bogotá esta en aumento así como la tendencia por el consumo de productos orgánicos y saludables. Bike Town Organic Juice, es una nueva propuesta que sale al mercado para ofrecerle al grupo objetivo la hidratación y los nutrientes necesarios para desempeñar y acompañar sus labores físicas de una forma 100\% natural. 
Esta bebida elaborada a base de fruta orgánica con componentes totalmente eco-amigables, busca desde su interior hasta su exterior impactar al público y acogerlo para que reconozca dentro el mercado un producto de alta calidad, con grandes beneficios y a un precio asequible.

Encontramos en su interior una bebida de fruta $100 \%$ orgánica, cultivada en suelos colombianos por manos campesinas, sin uso de fertilizantes artificiales ni pesticidas químicos. Entre algunas de las propiedades nutricionales de Bike Town Organic Juice cabe destacar que tiene los siguientes nutrientes: hierro, proteínas, calcio, carbohidratos, vitaminas $\mathrm{B}, \mathrm{C}, \mathrm{D}, \mathrm{E}, \mathrm{K}$, entre otras; que proporcionan en el consumidor un adecuado desempeño físico así como el correcto funcionamiento de su organismo.
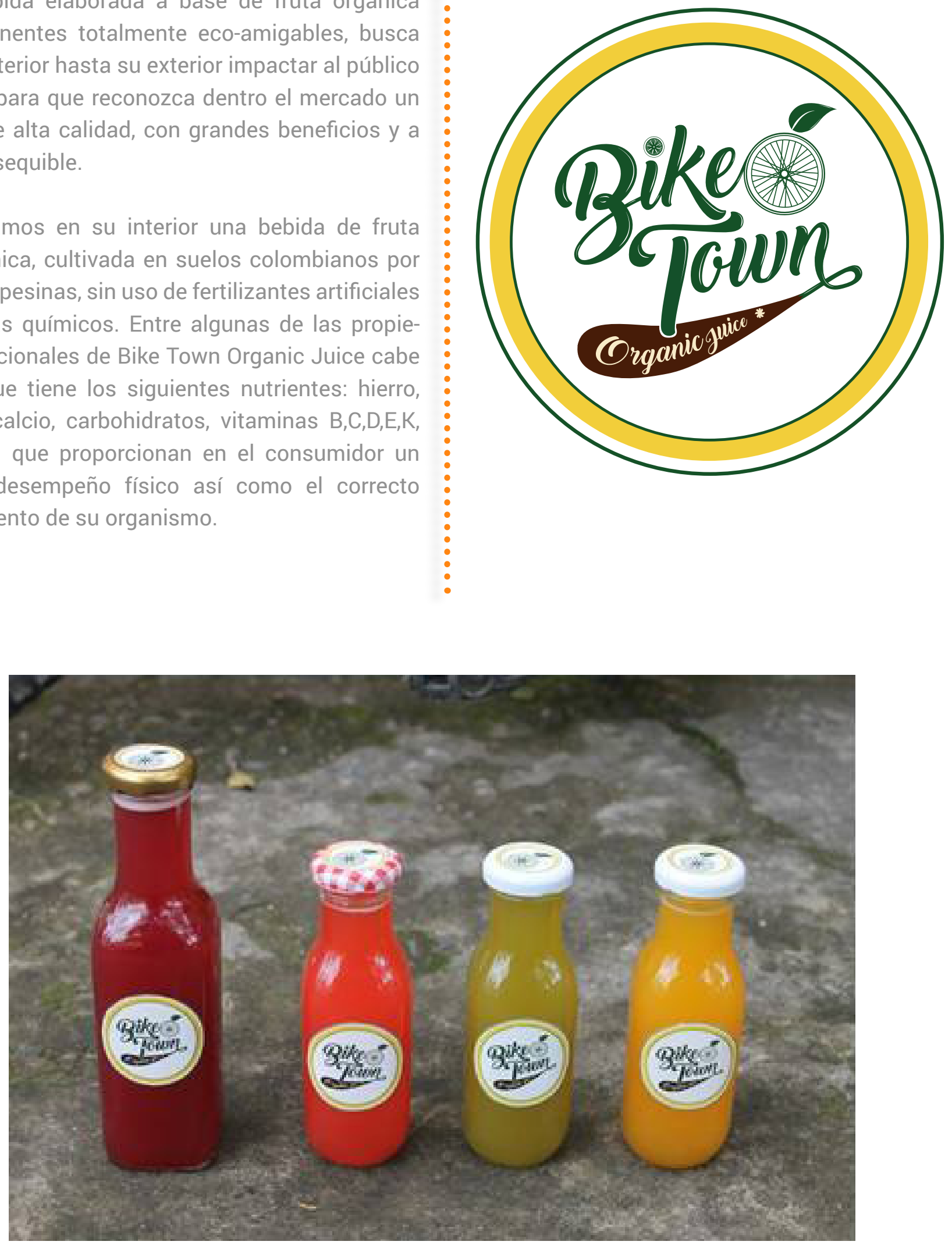

Muestra

Bike Town Organic Juice. 

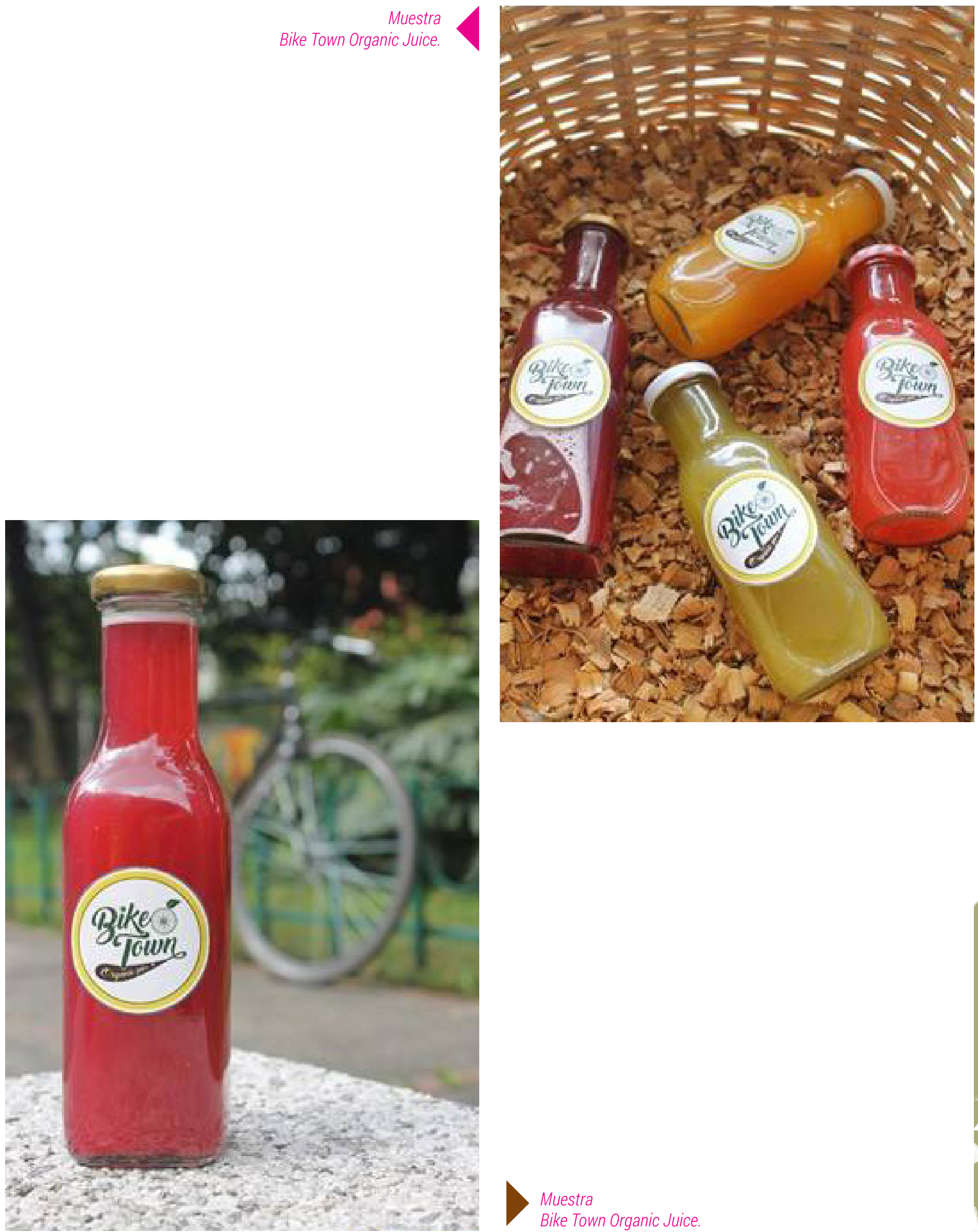
Por su bajo contenido en calorías, tomar Bike Town Organic Juice, es recomendable para mantenerse en línea. Si piensas en realizar una dieta para bajar de peso, puedes incluirlo en ella.

Bike Town Organic Juice es una marca fresca, orgánica, funcional y amigable con el medio ambiente, diseñada en pro de una vida saludable, que promueve con su empaque de vidrio un producto totalmente inocuo, reciclable y renovable, incitando al reúso y generando estabilidad en su entorno.

Posicionar Bike Town Organic Juice en el mercado como una marca líder en el segmento de bebidas orgánicas/saludables/deportivas, que genere confianza y recordación en la mente de los consumidores hace parte de los objetivos y filosofía de la marca. 


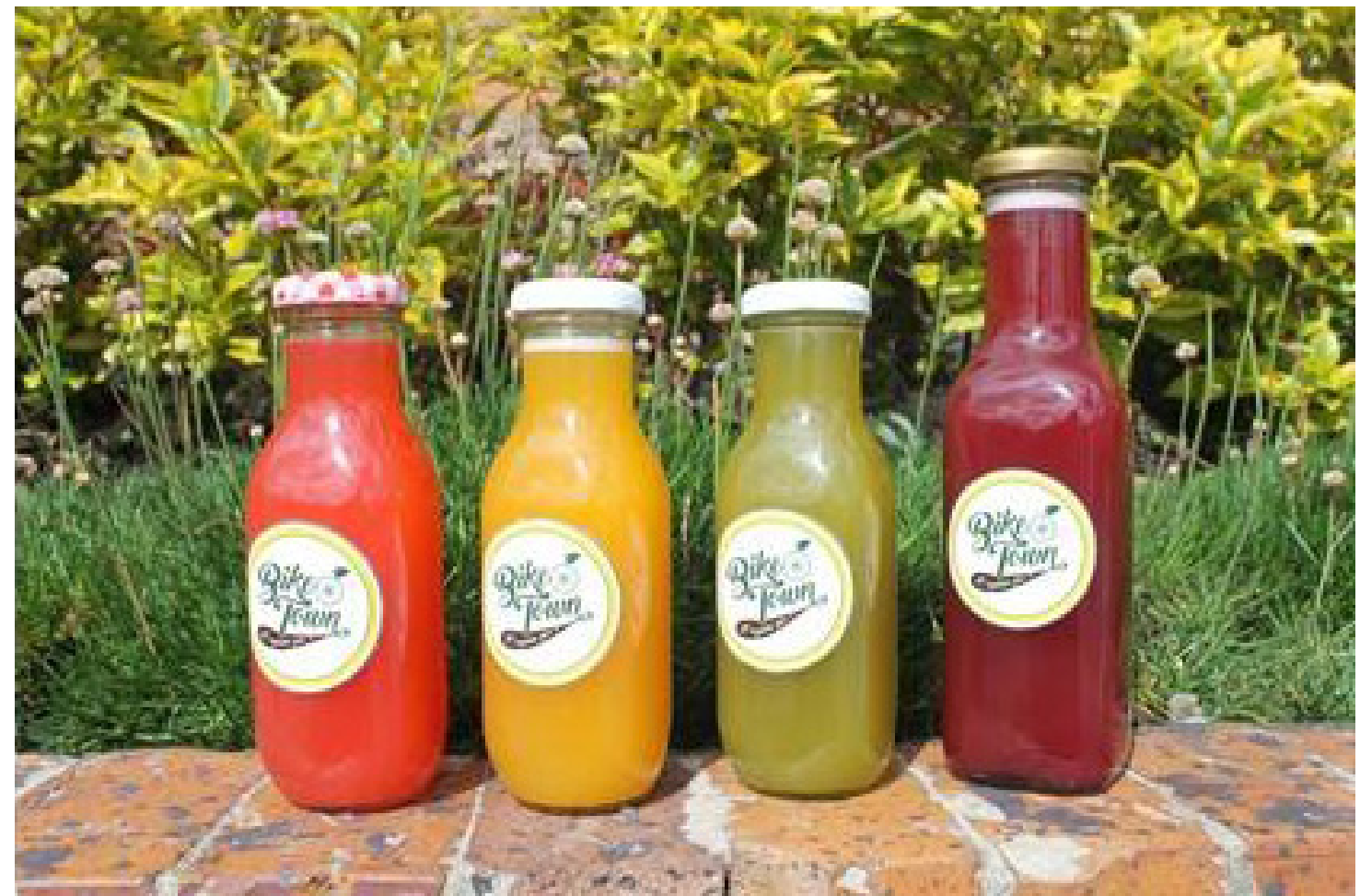

Muestra

Bike Town Organic Juice.

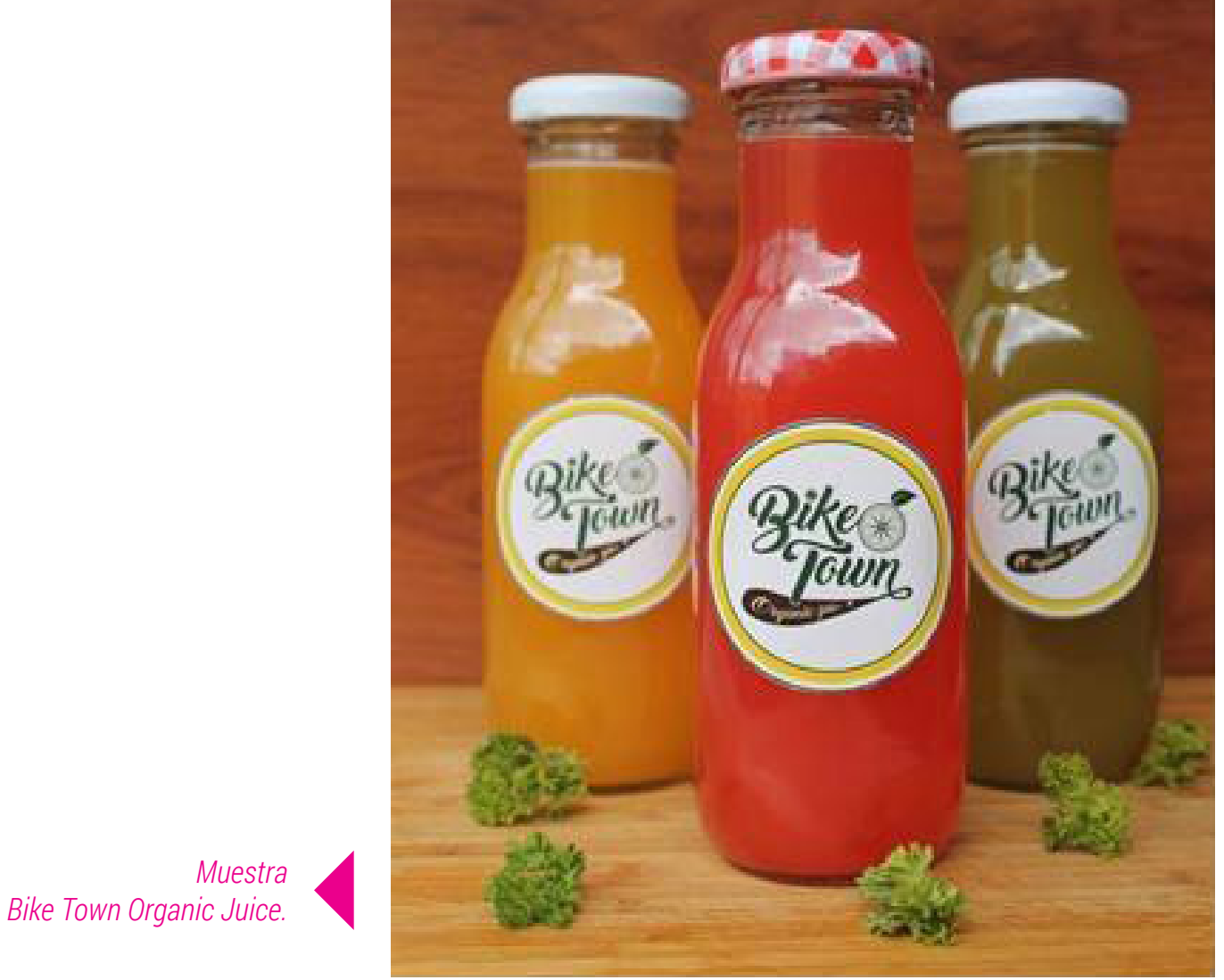




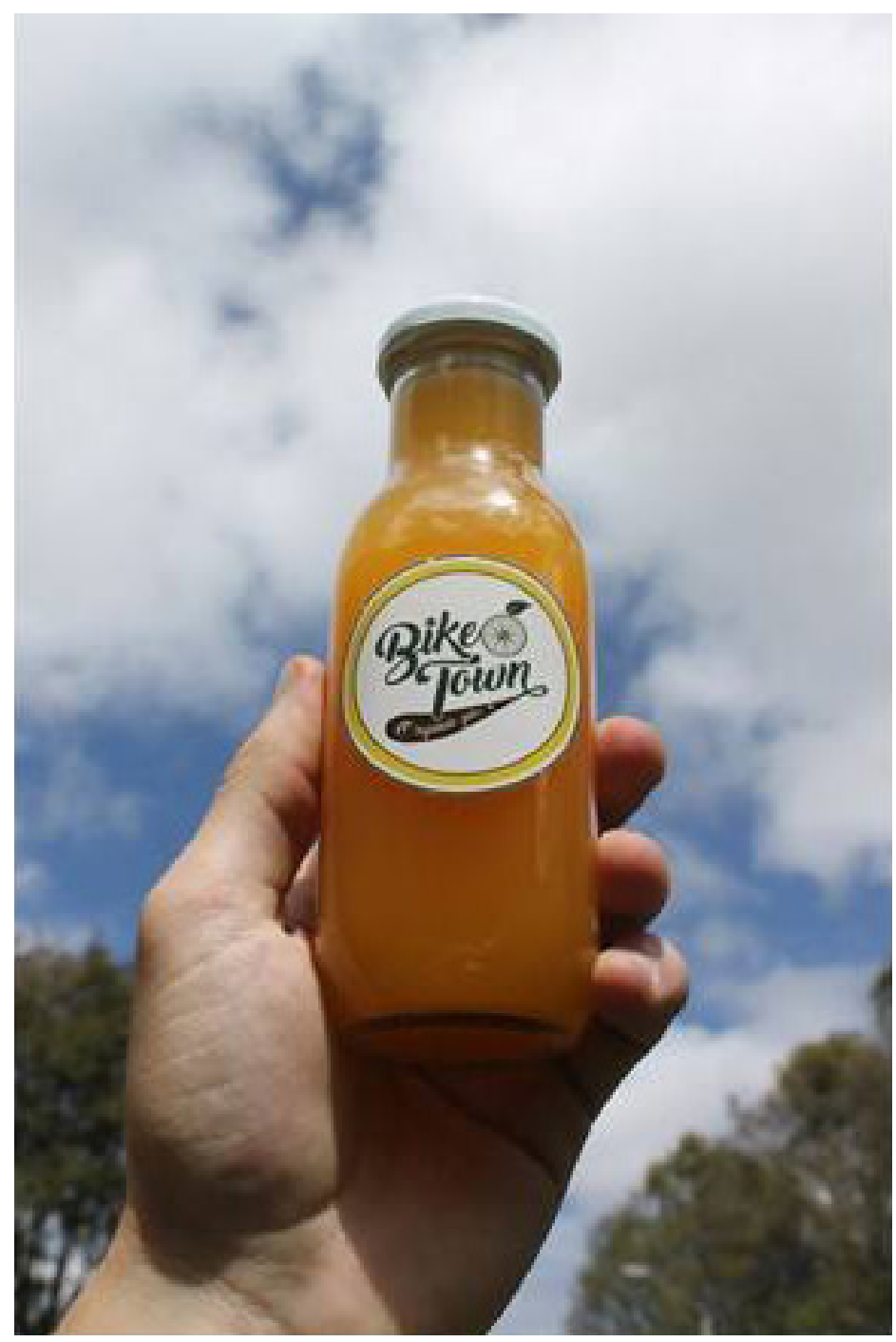

Muestra

Bike Town Organic Juice.

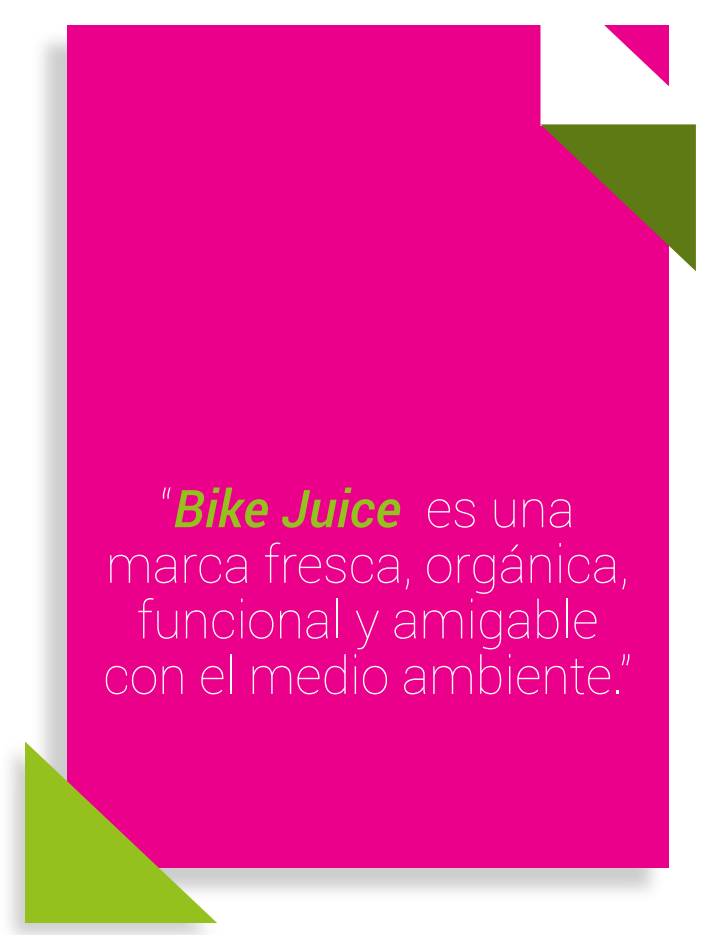

